\title{
Anthracnose disease dynamics of mango orchards in relation to humid thermal ratio under subtropical climatic condition
}

\author{
P.K. SHUKLA*, TARUNADAK and GUNDAPPA \\ Central Institute for Sub-tropical Horticulture, Rehmankhera, P.O. Kakori, Lucknow-226 101, Uttar Pradesh \\ *e-mailaddress: pksmush@gmail.com
}

\begin{abstract}
Incidence and severity of mango anthracnose was studied during 2013, 2014 and 2015 for its relation with weather parameters. Twenty two mango orchards of cv. Dashehari, aged between 20-35 years in Lucknow district of Uttar Pradesh were selected for this study. The statistical analysis at different locations indicated highest incidence of 40.0, 29.2 and 29.6 per cent in three years respectively. Differences in disease severity were also observed among the years and within the orchards. Cooler months had high humid thermal ratio (HTR) values and warmer months mostly had low (1.2 to 3.5) HTR values. Significant positive correlation was found between HTR and anthracnose incidence and severity. The study inferred that humid thermal ratio may be used for prediction of the disease as a ratio of agroadvisory services to recommend timely protection measures to the farmers.
\end{abstract}

Key words: Anthracnose, weather parameters, humid thermal ratio, correlation, mango

Mango is widely grown in India across diverse climatic conditions and is impacted by several pests and diseases. Anthracnose disease of mango is one of the most important diseases to cause severe losses to the mango fruit and in turn economical yield of the orchard (Ploetz, 1999). The conidia of Colletotrichum gloeosporioides may cause direct infection of tender leaves, stems, flowers and fruits. The preharvest infection of the fruits causes severe post harvest rot, which is responsible for lowering the marketing value (Swamy, 2012). Pandey et al. (2012) and Kamle et al. (2013) had studied the incidence and phylogenetic correlation in mango. Ann et al., (1994) observed that the weather parameters particularly rainfall, high relative humidity $(\mathrm{RH})$ and higher temperatures favour the disease development. The amount, frequency and distribution of rainfall also significantly influenced the anthracnose incidence on mango fruits.

Environmental factors and phenological stages are crucial in the development of the disease. Weather extremities profoundly influence critical mango phenological stages. Rajan (2012) reported that temperature and rainfall are the most important factors impacting the phenology of the crop and in turn associated crop-weather-pest and disease dynamics. Research reports are available on the role of different keyweather parameters like temperature, $\mathrm{RH}$ and rainfall on the disease prediction (Misra et al., 2004; Saha, and Das, 2014). The ratio of temperature and RH was used for determination of extent of variability in the outbreak of leaf spot disease (Ijaz et al., 2011). Based on four years field experimentation in Tikamgarh area of Madhya Pradesh, Gangwar et al. (2014) concluded that humid thermal ratio influence the leaf spot severity on groundnut. Based on these parameters around 72 per cent disease variability can be predicted. These studies may be helpful in delivering forewarning for adopting required control measures of pest and diseases (Saumi et al., 2005). Information on the impact of relative humidity and temperature ratio, two most important factors influencing disease development in not available and has not been studied for anthracnose disease. Hence, the present investigations were set out to assess the anthracnose dynamics using humid thermal ratio, based on datasets from 22 fixed plot mango orchards in Lucknow district.

\section{MATERIALS AND METHODS}

The present study was conducted in Lucknow district (26.54 $\mathrm{N}$ Latitude, $80.45^{\circ} \mathrm{E}$ Longitude and $127 \mathrm{~m}$ above mean sea level), Uttar Pradesh, India in 22 mango orchards (20-35 years) of cv. Dashehari. All these orchards were designated as fixed plots, which had trees planted at $10 \times 10$ $\mathrm{m}$ distance. Mango anthracnose disease incidence and severity appraised on these orchards during three consecutive years i.e. 2013, 2014 and 2015. Each orchard had at least 25 trees. Data on anthracnose were recorded on weekly basis from five randomly selected trees in four 
direction of the tree. Disease incidence and severity recorded from 10 shoots in each direction of tree. Disease incidence was calculated on the basis of total number of leaves and panicles observed on a tree and the number of leaves having disease symptoms. Incidence and severity was recorded from $1^{\text {st }}$ SMW to 52 ${ }^{\text {nd }}$ SMW during 2013 and 2014; however for 2015 , it is up to $30^{\text {th }}$ SMW (July). These data were used for further analysis and discussion.

Diseaseincidence $(\%)=\frac{\text { Number ofdiseased leaves observed }}{\text { Total number of leaves observed }} \times 100$

The disease severity was recorded as the per cent infected area and it was converted into 0-4 scale, where, 0 $=$ nil, $1=1-5 \%, 2=5.1-10 \%, 3=10.1-20 \%, 4=$ above $20 \%$. Per cent disease ratio was calculated as follows:

$$
\mathrm{PDI}=\frac{\text { Sum of all numerical ratings }}{\mathrm{Non} \text { of }} \times 100
$$

No. of leaves observed $\times$ Maximum rating

The experimental area was characterized as subtropical with hot dry summers and cold winters. Daily weather data of temperature (maximum and minimum), relative humidity (morning and evening), rainfall, wind speed, bright sunshine hours and evaporation rates were recorded in the agro meteorological observatory located within the experimental site. Further, weather data was used to calculate humid thermal ratio using following formulae (Jhorar et al., 1992).

$\mathrm{HTR}=\mathrm{RH}_{\text {mean }} / \mathrm{T}_{\text {mean }}$

where, HTR is humidity thermal ratio, $\mathrm{RH}_{\text {mean }}$ is mean relative humidity and $\mathrm{T}_{\text {mean }}$ is mean temperature.

Disease dynamics was plotted against years. Year wise histographic distribution of anthracnose was carried out by SPSS package (Version 16.0). Linear regression equations were generated by considering weather parameters as independent variables and anthracnose as dependent variables. Statistical significance of Pearson's correlation coefficients between dependent and independent variables under the study was drawn using t test significance. Functional relationship between HTR and anthracnose was carried out using MS Excel software.

\section{RESULTS AND DISCUSSION}

\section{Incidence and development of anthracnose on mango}

The statistical analysis showed wide variations in mango anthracnose incidence across 22 orchards and three years (Table 1). The analysis of mean incidence across the three consecutive years revealed that the highest incidence was 40.0,29.19 and 29.67 per cent. During the year 2013, highest anthracnose incidence $(40.0 \pm 0.80 \%)$ was recorded in Hafizkhera (Fixed plot-I) followed by $39.27 \pm 0.73$ per cent in Navipana (Fixed plot-I) orchard, while lowest one (34.65 \pm 0.57 ) was recorded in NB Dhanewa (Fixed plot-I). Similarly, lowest value of $23.96 \pm 1.20$ per cent incidence was observed in Allupur (Fixed plot-I) and highest as 29.19 \pm 1.63 in CISH Block III followed by $28.96 \pm 1.67$ in CISH Bolck II during the year 2014. The corresponding values were $26.27 \pm 0.29,29.67 \pm 0.35$ and $29.47 \pm 0.42$ per cent in Allupur, CISH Block II and Hafizkhera (Fixed plot-I) respectively during the year 2015 (Table 2). It was further noticed that some of the orchards had lowest incidence and coefficient of vartions between 9.6 to 17.3 per cent in 2013 and 2015 , in contrast to 2014 , had higher CV values (28.91 to 35.92 per cent) of disease incidences.

Differences in disease severity were also observed among the three years (Table 2). The progressive changes in disease severity were much more in the third year as compared to first and second year (Table 2). Highest severity of 14.42 \pm 0.14 PDI was observed in Navipana (Fixed plot I) followed by $14.39 \pm 0.18$ PDI in Navipana Fixed plot II with lowest in NB Dhanewa fixed plot I (12.29 \pm 0.08 PDI) during 2013. During 2014 year, Hafizhkhera Fixed plot I had highest PDI 13.62 \pm 0.70 while lowest was found as $10.25 \pm 0.38$ in Allupur Fixed plot II. A maximum of $18.81 \pm 0.33$ PDI was recorded in CISH Block II followed by $18.57 \pm 0.33$ PDI in Hafizhkhera (Fixed plot I) and with the lowest as 15.89 PDI in Allupur(Fixed plot II). The histographic representation indicated that the mean value of mango anthracnose incidence was 37.16 per cent during $2013(n=1144)$, while in next two years, it was 26.43 per cent $(n=1144)$ and 28.22 per cent $(n=660)$. The frequency distribution further explained that the anthracnose incidence was higher in the range of 30 to 40 per cent during 2013 while during 2014 and 2015 , it was widely distributed with 20 to 30 per cent and the highest frequency level of 50 to 100 per cent. To realize the wide variation in the anthracnose severity, histographic analysis revealed that the mean of anthracnose severity was 13.46, 12.15 and 17.30 PDI during 2013, 2014 and 2015 respectively.

Variations in disease incidence and severity are a function of exited microclimatic conditions within the crop canopy and also across years. Shew et al. (1988) found that the genotypes with partial resistance to late leaf spot proved 

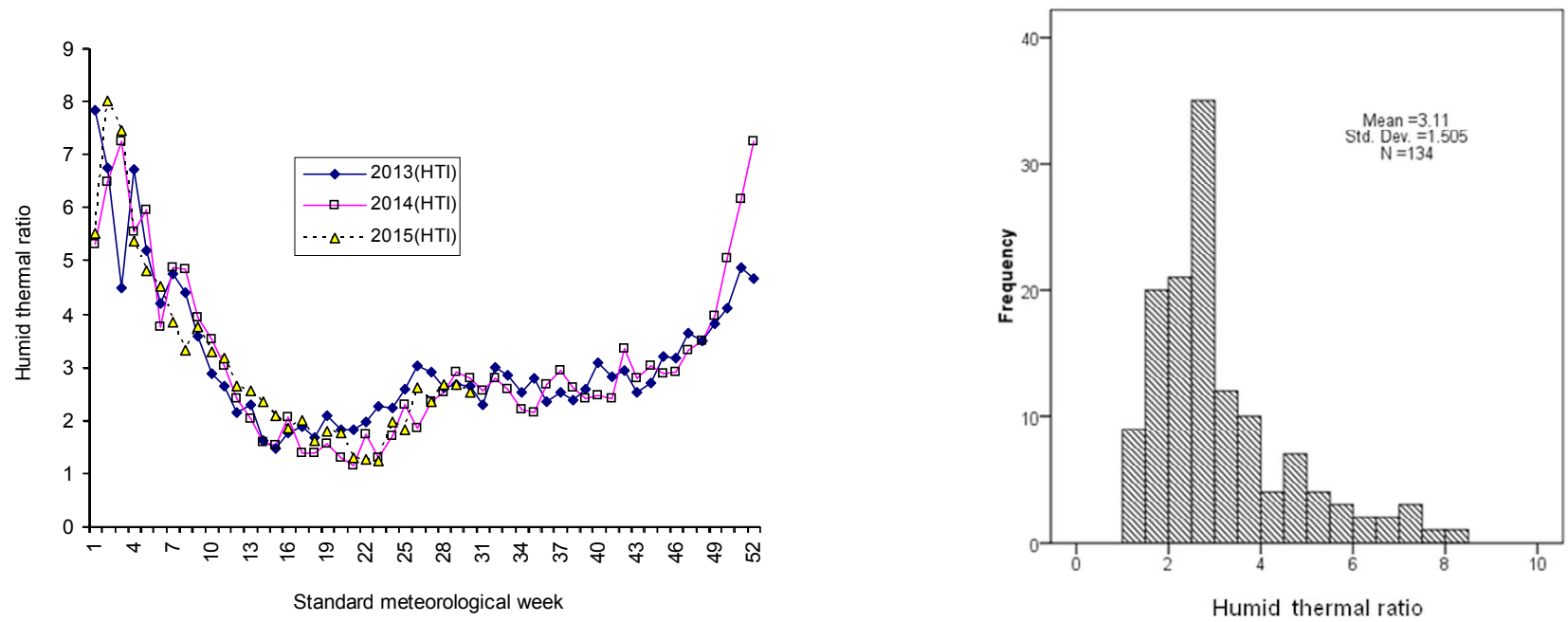

Fig. 1: Variations in humid thermal ratio during the study periods and its frequency distribution
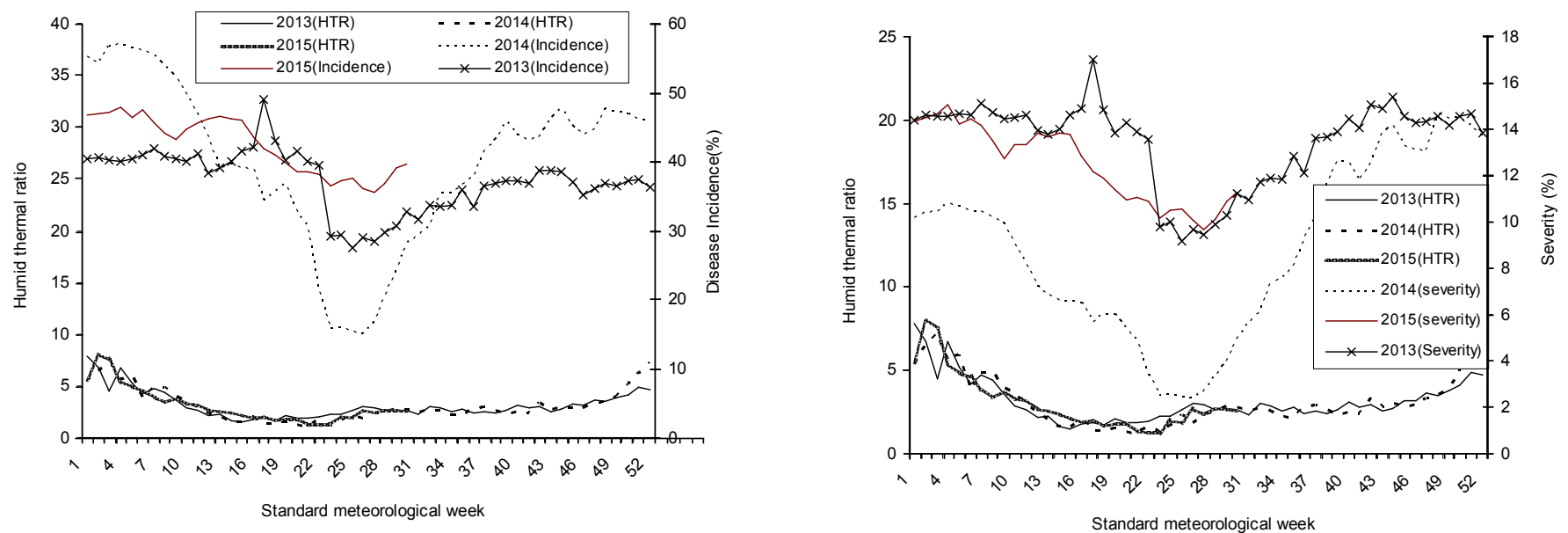

Fig. 2: Dynamics of incidence and severity of disease

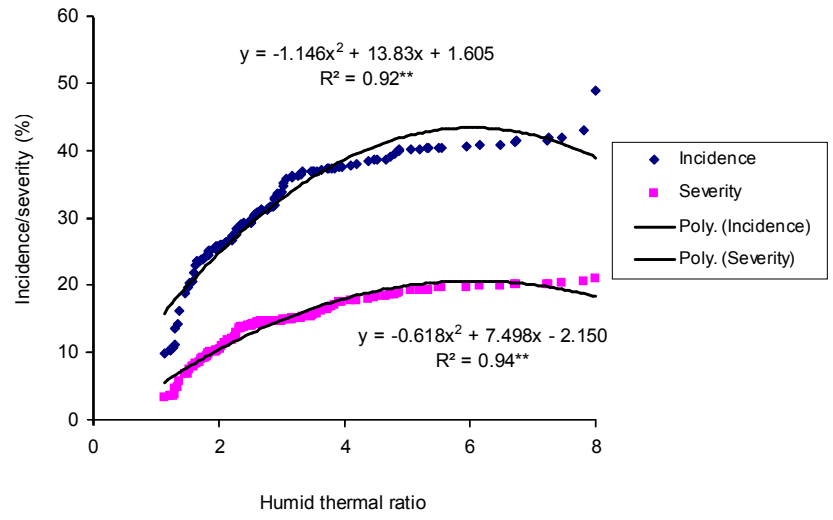

Fig. 3: Correlation between incidence and severity of disease with HTR

most sensitive to high temperatures. Ijaz et al. (2011) reported Cercospora leaf spot prediction based on humid thermal ratio and forecasted $80-94 \%$ in susceptible genotypes and $64-93 \%$ in partially resistant genotypes during 2003, 2004 and 2005 respectively.

\section{Relationship between humid thermal ratio with anthracnose incidence and development}

Results revealed that the estimated humid thermal ratio widely varied during the year and variations across the years were also observed (Fig. 1). Values ranged between 3.0- 8.0 during January - March months. It indicates that 


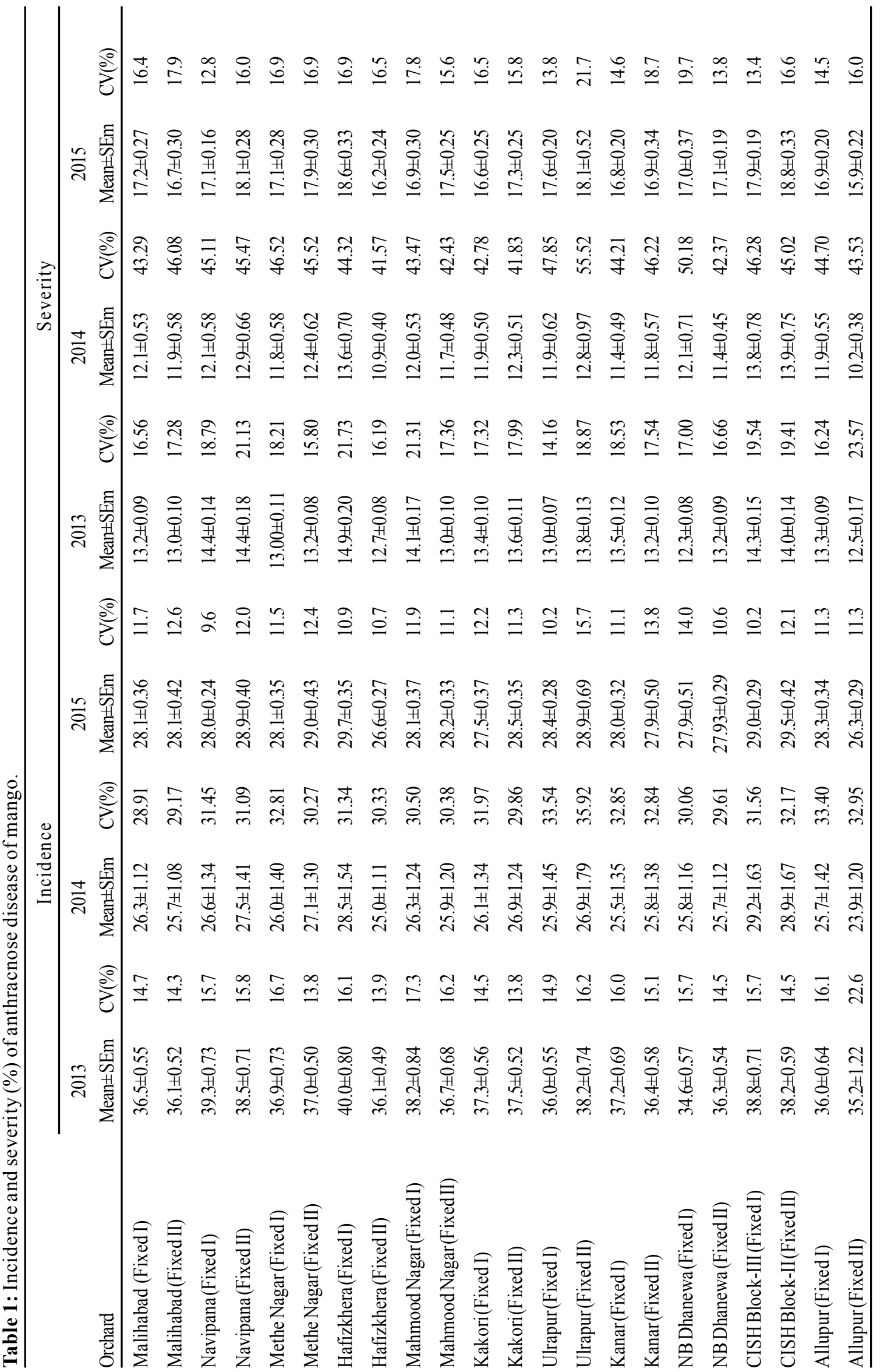


cooler months had higher HTR as the temperature in the denominator was lower during these periods. Phenological events like vegetative flushes and initiation of flowering were occurred during these months. As the phenological stage advanced and with the onset of higher temperature during April to October, the ratio started declining and mostly ranged from 1.2 to 3.5 . The frequency distribution further showed that the mean value of HTR was 3.11 ( $\mathrm{n}=$ 134). Towards the end of year, during cooler months of November and December, the ratio values started increasing once again. The lowest and highest values of the humid thermal ratio were 1.47 to 7.82 during the year $2013,1.13$ to 7.25 during 2014 and 1.23 to 8.0 in the third year. The pictorial presentation of HTR with disease incidence and severity (Fig. 2) depicts that both the incidence and severity exhibited decreasing trend in the 2014 as compared to other years between 20 to 30 standard meteorological weeks. The probable reason is that the rainfall was almost absent i.e. weekly average rainfall was only 0.4 to $12.4 \mathrm{~mm}$ between 24 to 33 SMW during 2014 while in 2013, in each week there was a sufficient rainfall (weekly average of 1.29, 15.47, 23.34, 6.51, 11.14, 7.0, 13.29, 13.71 and $21.74 \mathrm{~mm}$ rainfall received). Likewise in 2015 year also sufficient rains occurred, which could have contributed to the severe infection and development of the anthracnose. Not only rainfall, but $\mathrm{RH}_{\text {min }}$ was also lower in 2014. Thus, rainfall plays a major role in the incidence and severity of this disease on mango. Kaur et al. (2007) also observed that relative humidity (RH), rainfall and number of rainy days are the most important weather parameters indicating favourable role in the development of karnal bunt disease. Rainfall accompanied by high RH contributing major part for karnal bunt disease in wheat and it was estimated that the variability of occurrence of karnal bunt in the Karnal zone of Haryana state was up to $76 \%$ with the help of weather parameters (Singh et al., 2013). Gangwar et al. (2014) concluded that maximum disease severity of leaf spot in groundnut was observed when the HTR values were near to 3.0 during 2011 while in the next year; higher values observed when mean temperature was $26^{\circ} \mathrm{C}$. In such a situation progression of the disease was restricted. Actually, biotic and abiotic factors predominantly plays havoc role at critical phenological stages of mango as it grow in open field conditions. Crop weather interaction and associated disease dynamics are thus become vulnerable under the ambit of ambient temperature, relative humidity and precipitation. Jensen and Boyle (1965) reported that RH was most favourable for leaf spot development. The humid thermal ratio/ratio was best known and applied for disease risk assessment world over and in India too (Wangikar and Shukla, 1977; Baker et al., 2000; Jhorar et al., 1992; Mavi et al., 1992). Lin et al. (2015) observed that the pest and disease dynamics in mango are profoundly influenced by the biotic and abiotic factors, even in an identical environment and also suggested that relative humidity and temperature are the most crucial factor. Thus, in this study we have considered the humid thermal ratio to assess the anthracnose disease dynamics. The significant positive correlation was found between HTR and anthracnose incidence and severity during all the years. The pooled data also showed significant positive correlation between humid thermal ratio and disease incidence and severity. The best fit polynomial second order regression had explained up to 9294 per cent of variations in incidence and severity (Fig. 3). Hence, this clearly indicates that humid thermal ratio may serve the purpose of forecasting and agroadvisory for timely control measures of the disease.

\section{CONCLUSION}

From the present study it is inferred that weather parameters particularly rainfall, temperature and relative humidity plays a pivotal role on the incidence and variations in mango anthracnose across the years and orchards. The disease dynamics were lower in 2014 due to absence of sufficient rainfall while in other two years, because of predominance and occurrence of sufficient rainfall, incidence and severity of mango anthracnose was higher. Across different orchards, incidence and severity varied mainly because of the microclimatic situation exited thereof and the control measures adopted by the farmers. Positive correlation of anthracnose incidence and severity to humid thermal ratio suggested that this ratio may explain the variations in anthracnose dynamics to a greater extent.

\section{ACKNOWLEDGEMENTS}

Authors are thankful to Indian Council of Agricultural Research, New Delhi for providing financial support under National Initiative of Climate Resilient Agriculture (NICRA) Project entitled, "Understanding the changes in host pest interactions and dynamics in mango under climate change scenario". Director, CISH, Lucknow is also duly acknowledged for facilitating the work.

\section{REFERENCES}

Ann, P.J., Huang, R.C. and Chen, M.F. (1994). Effects of environmental factors on disease incidence of mango 
anthracnose. Plant Pathology Bulletin, 3(1): 34-44.

Baker, R.H.A., Sansford, C.E., Jarvis C.H., Cannon, R.J.C., MacLeodAand Walters K.F.A. 2000. The role of climatic mapping in predicting the potential distribution of nonindigenous pests under current nad future climates. Agric Ecosys Environ, 82:57-71.

Gangwar, R.K., Srivastava,A.K., Prajapati, R.K., and Rathore, S.S. (2014). Weather based forewarning model of Groundnut leaf spot disease in arid and semi-arid regions of India. J. Mycol. Pl. Pathol., 44(4): 405-411.

Ijaz, M., Haque, M.I., Rauf, C.A., fayyaz-ul-hassan, Riaz,A. and Mughal, S.M.(2011). Correlation betweenhumid thermal ratio and epidemics of Cercospora leaf spot of Peanut in Pothwar. Pak. J. Bot., 43(4): 2011-2016.

Jhorar, O.P., Mavi, H.S., Sharma, I., Mahi, G.S., Mathauda, S.S. and Singh, S. (1992). A biometeorological model for forecasting Karnal bunt disease of wheat. Pl. Dis. Rep., 76: 204-209.

Kamle, M., Kumar P., Gupta, V.K., Tiwari, A.K., Misra, A.K., Pandey, B.K. (2013). Identification and phylogenetic correlation among Colletotrichum gloeosporioides pathogen of anthracnose for mango. Biocatal. Agric. Biotechnol., 2: 285-287.

Kaur, G., Kaur, S. and Hundal, S.S. (2007). Weather based empirical model to predict infective sporidial stage of Tilletia indicaduring wheat crop season. Ind. Phytopathol., 60(2):173-179.

Lin, C.N., Wei, M.Y., Chang, N.T. and Chuang, Y.Y.(2015). The occurrence of Scirtothrips dorsalis Hood in mango orchards and factors influencing its population dynamics in Taiwan. J. Asia-Pacific Entomol., 18: 361-367.

Mavi, S.S., Jhorar, O.P., Sharma, I., Mahi, G.S., Mathauda, S.S. and Aujia, S.S. (1992). Forecasting Karnal bunt disease of wheat- agrometeorological method. Cereal Res. Comm., 20: 744-767.

Misra, A.K., Om Prakash and Ramasubramanian, V. (2004). Forewarning powdery mildew caused by Oidium mangiferae in mango (Mangifera indica) using logistic regression models. Indian J. Agric. Sci., 74: 1-4.
Narjary B., Adak T., Meena M.D. and Chakravarty N.V.K. (2013). Population Dynamics of MustardAphid in relation to Humid Thermal Ratio and Growing Degree Days. J. Agril. Physics., 13(1): 39-47.

Pandey,A., Yadava, L.P., Misra, R.K., Pandey, B.K., Muthukumar, M., Chauhan, U.K. (2012). Studies on the incident and pathogenesis of Colletotrichum gloeosporioides penz. causes anthracnose of mango. Int. J. Sci. Nat., 3: 220232.

Ploetz, R. (1999). Anthracnose: the most important disease in much of the mango producing world. News Lett. Plant Pathol., 3: 1-6.

Rajan, S. (2012). Phenological responses to temperature and Rainfall: ACase Study ofMango. In: Tropical Fruit Tree Species and Climate Change: Sthapit BR, Ramanatha Rao V, Sthapit SR. (Eds), Bioversity International, New Delhi, India, pp. 71-96.

Saha, P. and Das, S. (2014). Development of prediction equations for early blight leaf spot on tomato under different fungicides treatments. J. Agrometeorol., 16(1):130136.

Saumi, R.P., Chattopadhyay, N. and Ravindra, P.S. (2005). Forewarning of incidence of tikka disease on groundnut and operational crop protection using weather information in Gujarat. Mausam, 56: 425-432.

Singh, R., Karwasra, S.S., Biswas, B. and Singh, D. (2013). Development of predictive model for karnal bunt of wheat. J. Agrometeorol., 15(special issue-I):112-114.

Swamy, J.S. (2012). Anthracnose-a devastating pre and postharvest disease of mango. Int. J. Plant Prot., 5(2): 429 437.

Shew, B.B., Beute, M.K. and Wynne, J.C. (1988). Effects of temperature and relative humidity on Expression of resistance to Cercosporidium personatum in peanut. Phytopathol., 78(4): 493-498.

Wangikar, P.D. and Shukla, V. N. (1977). Influence of prevailing temperature and humidity on tikka disease of groundnut. J. Mah. Agric. Univ. 2: 259-264. 